\title{
Assessment of determinants of polycystic ovarian syndrome in women in reproductive age group attending tertiary healthcare facility in southern Maharashtra
}

\author{
Varun Gaitonde ${ }^{1, *}$, Supriya Patil ${ }^{2}$, Sanjaykumar Patil ${ }^{3}$, Yamini Patil ${ }^{4}$ \\ ${ }^{1}$ Junior Resident, ${ }^{2,3}$ Professor, ${ }^{4}$ Associate Professor, Dept. of Obstetrics and Gynecology, Krishna Institute of Medical Sciences, \\ Karad, Maharashtra, India
}

*Corresponding Author:

Email: varun.gaitonde@gmail.com

Received: $12^{\text {th }}$ March, 2018

Accepted: $13^{\text {th }}$ April, 2018

\begin{abstract}
Introduction: Pathophysiology of PCOS reveals excessive ovarian and/or adrenal androgen secretion results in hyperandrogenism and is associated clinical manifestations ranging from hirsutism, acne, male-pattern baldness to irregular menses, infertility. This study aims at assessing the prevalence and clinical presentations of PCOS among women of the reproductive age group attending the OPD of a tertiary care centre.

Materials and Methods: The study was carried women of reproductive age group (15-45yrs) attending Obstetrics and Gynaecology OPD of a tertiary care hospital presenting with relevant symptoms from July 2015 to July 2017.

Results: In the present study, the average age of participant was $22.47+3.44$ years, we also found that menstrual abnormalities were observed among all the study participants followed by skin discolouration (32.4\%). Average BMI in $\mathrm{kg} / \mathrm{m} 2 \mathrm{was} 22.22+$ 2.22 .

Conclusions: PCOS in a common disorder among young women. Menstrual problems are the commonest reason for gynecological OPD consultation among adolescent girls. Evaluation of bleeding problems in adolescents is justified, before considering them as normal physiological transition.
\end{abstract}

Keywords: Polycystic ovarian syndrome (PCOS), Menstrual abnormalities, Hyperandrogenism in women, Reproductive age women, Infertility.

\section{Introduction}

The spectrum of polycystic ovary syndrome (PCOS) is characterized by hyperandrogenism, ovulatory dysfunction and polycystic ovaries (PCO). Pathophysiology reveals excessive ovarian and/or adrenal androgen secretion results in hyperandrogenism and is associated clinical manifestations such as hirsutism, acne and male-pattern baldness. Ovulatory dysfunction may include chronic anovulation and is associated with menstrual disturbances and infertility. ${ }^{1}$ PCO is characterized by an increased number of small antral follicles with arrested development and a hypertrophied theca cell layer. ${ }^{2}$ In addition to hirsutism, irregular menses, and infertility, women with PCOS display a number of metabolic abnormalities including hyperinsulinemia, insulin resistance, dyslipidemia, and obesity. ${ }^{3}$ All these features are components of the metabolic syndrome, and women with PCOS are therefore at risk of developing type 2 diabetes (T2DM) which, in turn, puts them at increased risk of developing cardiovascular disease (CVD). ${ }^{3}$

This study aims at assessing the prevalence of women of the 15-30yrs age group attending the OPD of a tertiary care centre, suffering from PCOS \&studying the various clinical aspects of this syndrome in them to determine the gravity of the problem.

\section{Materials and Methods}

The study was carried women of reproductive age group (15-45yrs) attending Obstetrics and Gynaecology OPD of a tertiary care hospital presenting with relevant symptoms from July 2015 to July 2017. According to some previous studies done in this direction the prevalence of $10 \%$ was considered for calculating the sample size for the study. The sample size was calculated at $95 \%$ confidence level and with relative precision of $20 \%$. It was then adjusted for finite population and a $10 \%$ non response rate was accounted. The sample size calculated for this study was 480 patients. In all 500 patients were studied over the study period of 2 years. Women in the reproductive age group (15-45yrs) who have consented and women who had attained menarche at least more than 2 years before the study women who have come to seek treatment from Obstetrics and Gynaecology OPD of Krishna hospital for menstrual complaints (irregular menses/oligomenorrhea) signs or symptoms of hyperandrogenemia or $\therefore$ abdominal USG showing at least 12 follicles $(2-9 \mathrm{~mm}$ in diameter) arranged peripherally around a dense core of ovarian stroma or scattered throughout an increased amount of stroma in at least 1 ovary and diagnosed as PCOS according to rotterdam 2003 criteria were included in the study. ${ }^{4}$

Women not in the reproductive age group women within 2 years of attaining menarche women who are pregnant women having any major systemic illness, 
congenital adrenal hyperplasia, hyperprolactinemia, acromegaly, functional hypothalamic amenorrhea, and patients receiving drugs for any other systemic illness (except hypothyroidism) were excluded from the study.

Operational Definitions: The definition of PCOS, in 1990, when it was first described by National Institute of Health (NIH) included hyperandrogenism and ovulatory dysfunction but did not include polycystic ovarian morphology on ultrasonography as a necessary criterion for diagnosis. Much later, in the year 2004, the rotterdam criterion was formulated by the PCOS consensus workshop group, (Rotterdam ESHRE/ASRM-sponsored PCOS consensus workshop group) according to which PCOS was defined as presence of any two of the three features: oligo/amenorrhea, clinical and/or biochemical hyperandrogenism, and polycystic ovaries. ${ }^{4}$

Oligo/amenorrhea: absence of menstruation for 45 days or more and/or $\leq 8$ menses per year.

Clinical Hyperandrogenism: Modified ferriman and gallway (mFG) score of 6 or higher. Using $\mathrm{mF}-\mathrm{G}$, some researchers reported a value as low as 3, which was abnormal. However, other investigators have used the 95th percentile of controls as the upper normal limit, which corresponds to an $\mathrm{mF}-\mathrm{G}$ score of $6-8$ in the population studied. We used an $\mathrm{mF}-\mathrm{G}$ score of 6 as the upper normal limit in accordance with a study in South Asia by Chen et $\mathrm{al}^{5}$ because there are no studies defining the criteria for Hirsutism in Indian girls.

Biochemical Hyperandrogenism: Serum testosterone level of $>76 \mathrm{ng} / \mathrm{dl}$ in the absence of other causes of hyperandrogenism.

Polycystic Ovaries: Presence of $>10$ cysts, $2-8 \mathrm{~mm}$ in diameter, usually combined with increased ovarian volume of $>10 \mathrm{~cm}$, and an echo-dense stroma in pelvic ultrasound scan.

The data was collected using standard case record proforma and entered in MS Excel spread sheet and was analysed using STATA-MP version 13. Data is summarized using descriptive statistics in present study. Continuous data is presented in form of Mean \pm SD whereas categorical data is presented in form of frequency and percentage. Analysis of variance (ANOVA) has been used to check difference in mean values between more than two groups. Post Hoc test is applied for multiple comparisons. Throughout the result significance level is set at $5 \%$.

\section{Observations and Results}

The present study was conducted among women in reproductive age group attending outpatient department under department of obstetrics and gynecology, at a tertiary healthcare center in southern Maharashtra. From the present study, we observed that average age in years was $22.47+3.44$ and in a range of 16 to 32 years. Majority of study participants belonged to age group
21-25 years (60\%), followed by participants of age less than 20 years (Table 1). Average age at menarche in years was $13.52+1.28$ and in a range of 11 to 17 years. We also found that in majority of cases $(82.5 \%)$, age at menarche was less than 15 years. Majority of study participants were unmarried $(86 \%)$, and were having no relevant family history in context of thyroid disorders $(91.4 \%)$. From the present study we observed that marital status and relevant family history was found to have significant association with occurence of PCOS (Table 1). Upon eliciting their lifestyle pattern, we reported that majority of study participats were having sedentary lifestyle $(75 \%)$, no habit of regular exercising $(95.4 \%)$, and had mixed pattern of diet $(61 \%)$. Though the findings were not found statistically significant (Table 1).

We recorded various modes of presentations of PCOS among our study participants, found that menstrual abnormalities were observed among all the study participants followed by skin discolouration $(32.4 \%)$, weight gain $(21 \%)$, acne $(13.4 \%)$, excessive hair loss (13.2\%), infertility (5\%). $21 \%$ study participants had a known history of thyroid disorders. Presence of skin discolouration, hirsuitism and infertility among cases of PCOS was found to be statistically significant (Table 2). We also recorded anthropometric measurements of our study participants. Average height in $\mathrm{cm}$ was $152.2+4.51$ and in a range of 142 to $161 \mathrm{~cm}$ whereas Average Weight in $\mathrm{kg}$ was $55.87+8.31$ and in a range of 32 to $72 \mathrm{~kg}$. We calculated their BMI using above values. Average BMI in $\mathrm{kg} / \mathrm{m} 2$ was $22.22+2.22$ and in a range of 17.4 to $27.8 \mathrm{~kg} / \mathrm{m} 2$. Average WHR was $0.8+0.04$ and in a range of 0.66 to 0.87 . Presence of BMI above 25 and occurence of PCOS was found to be statistically significant in our study (Table 3). In present study majority $41.17 \%$ had phenotype 4 , followed by $36.47 \%$ had phenotype 1 , followed by $15.29 \%$ had type 2 and $7.05 \%$ had type 3 (Table 4 ). This study found total 85 cases of clinically diagnosed PCOS, while only in 73 cases we found polycystic pattern in ovaries when confirmed using ultrasonography. The mean modified Ferriman-Galeway score was $6.32+3.33$ in a range of 2 to 30 . Majority 94.85 had score $<8$ and only $5.2 \%$ had $>8$ (Table 5). 
Table 1: Distribution of study participants according to their demographic characteristics and lifestyle patterns

\begin{tabular}{|c|c|c|c|c|}
\hline S. No. & \multicolumn{2}{|c|}{ Variable } & Frequency & P-value (if any) \\
\hline \multirow{3}{*}{1.} & \multirow{3}{*}{ Age group } & $<20$ & $130(26 \%)$ & \multirow{3}{*}{0.7} \\
\hline & & $21-25$ & $302(60.4 \%)$ & \\
\hline & & $>25$ & $68(13.6 \%)$ & \\
\hline \multirow{2}{*}{2.} & \multirow{2}{*}{ Age at menarche } & $<15$ & $411(82.2 \%)$ & \multirow{2}{*}{0.1} \\
\hline & & $>15$ & $89(17.8 \%)$ & \\
\hline \multirow{2}{*}{3.} & \multirow{2}{*}{ Marital status } & Married & $69(13.8 \%)$ & \multirow{2}{*}{$<0.005$} \\
\hline & & Unmarried & $431(86.2 \%)$ & \\
\hline \multirow{2}{*}{4.} & \multirow{2}{*}{ Relevant family history } & Yes & $43(8.6 \%)$ & \multirow{2}{*}{$<0.005$} \\
\hline & & No & $457(91.4 \%)$ & \\
\hline \multirow{2}{*}{5.} & \multirow{2}{*}{ Lifestyle pattern } & Sedentary & $375(75 \%)$ & \multirow{2}{*}{0.04} \\
\hline & & Non-sedentary & $125(25 \%)$ & \\
\hline \multirow{2}{*}{6.} & \multirow{2}{*}{ Regular exercise } & Yes & $23(4.6 \%)$ & \multirow{2}{*}{0.13} \\
\hline & & No & $477(95.4 \%)$ & \\
\hline \multirow{2}{*}{7.} & \multirow{2}{*}{ Diet pattern } & Mixed & $305(61 \%)$ & \multirow{2}{*}{0.29} \\
\hline & & Vegetarian & $195(39 \%)$ & \\
\hline
\end{tabular}

Table 2: Distribution of study participants according to their clinical features at presentation

\begin{tabular}{|c|c|c|c|c|}
\hline S. No. & \multicolumn{2}{|c|}{ Variables } & Frequency & P-value (if any) \\
\hline \multirow{2}{*}{1.} & \multirow{2}{*}{ Menstrual abnormalities } & Yes & $500(100 \%)$ & \multirow[b]{2}{*}{---} \\
\hline & & No & 0 & \\
\hline \multirow{2}{*}{2.} & \multirow{2}{*}{ Hirsuitism } & Yes & $29(5.8 \%)$ & \multirow{2}{*}{$<0.005$} \\
\hline & & No & $471(94.2 \%)$ & \\
\hline \multirow{2}{*}{3.} & \multirow{2}{*}{ Acne } & Yes & $67(13.4 \%)$ & \multirow{2}{*}{0.44} \\
\hline & & No & $433(86.6 \%)$ & \\
\hline \multirow{3}{*}{4.} & \multirow{3}{*}{ Infertility } & Yes & $25(5 \%)$ & \multirow{3}{*}{$<0.005$} \\
\hline & & No & $44(8.8 \%)$ & \\
\hline & & Not applicable & $431(86.2 \%)$ & \\
\hline \multirow{2}{*}{5.} & \multirow{2}{*}{ Excessive hair loss } & Yes & $66(13.2 \%)$ & \multirow{2}{*}{0.33} \\
\hline & & No & $434(86.8 \%)$ & \\
\hline \multirow{2}{*}{6.} & \multirow{2}{*}{ Weight gain } & Yes & $106(21.1 \%)$ & \multirow{2}{*}{0.03} \\
\hline & & No & $394(78.8 \%)$ & \\
\hline \multirow{2}{*}{7.} & \multirow{2}{*}{ Skin discolouration } & Yes & $163(32.6 \%)$ & \multirow{2}{*}{0.006} \\
\hline & & No & $337(67.4 \%)$ & \\
\hline \multirow{2}{*}{8.} & \multirow{2}{*}{$\begin{array}{l}\text { Known history of Thyroid } \\
\text { disorders }\end{array}$} & Yes & $105(21 \%)$ & \\
\hline & & No & $395(79 \%)$ & \\
\hline
\end{tabular}

Table 3: Distribution of cases according to their anthropometric findings

\begin{tabular}{|c|c|c|c|c|}
\hline S. No. & \multicolumn{2}{|c|}{ Variable } & Frequency & P-value (if any) \\
\hline \multirow{2}{*}{1.} & \multirow{2}{*}{ Height } & $<150$ & $189(37.8 \%)$ & \multirow{2}{*}{0.7} \\
\hline & & $>150$ & $311(62.2 \%)$ & \\
\hline \multirow{2}{*}{2.} & \multirow{2}{*}{ Weight } & $<<50$ & $99(19.8 \%)$ & \multirow{2}{*}{0.005} \\
\hline & & $>50$ & $401(80.2 \%)$ & \\
\hline \multirow{2}{*}{3.} & \multirow{2}{*}{ BMI } & $<25$ & $448(89.6 \%)$ & \multirow{2}{*}{0.002} \\
\hline & & $>25$ & $52(10.4 \%)$ & \\
\hline \multirow{2}{*}{4.} & \multirow{2}{*}{ WHR } & $<0,8$ & $204(40.8 \%)$ & \multirow{2}{*}{1} \\
\hline & & $>0.8$ & $296(59.2 \%)$ & \\
\hline
\end{tabular}

Table 4: Distribution of cases according to investigations and diagnosis (PCOS cases, $n=85$ )

\begin{tabular}{|l|c|c|}
\hline Phenotype & Frequency & Percentage \\
\hline Type 1 & 31 & $36.47 \%$ \\
\hline Type 2 & 12 & $15.29 \%$ \\
\hline Type 3 & 6 & $7.05 \%$ \\
\hline Type 4 & 35 & $41.17 \%$ \\
\hline Total & 85 & $100 \%$ \\
\hline
\end{tabular}


Table 5: Distribution of cases according to investigations and diagnosis

\begin{tabular}{|c|c|c|c|c|}
\hline S. No. & Variables & & Frequency & P-value (if any) \\
\hline \multirow{2}{*}{1} & \multirow{2}{*}{$\begin{array}{l}\text { Diagnosed as a PCOD } \\
\text { clinically }\end{array}$} & Yes & $85(17 \%)$ & \multirow{2}{*}{---} \\
\hline & & No & $415(83 \%)$ & \\
\hline \multirow{2}{*}{2} & \multirow{2}{*}{$\begin{array}{c}\text { Polycystic pattern seen on } \\
\text { USG }\end{array}$} & Yes & $73(14.6 \%)$ & \multirow{2}{*}{---} \\
\hline & & No & $427(85.4 \%)$ & \\
\hline \multirow{2}{*}{3} & \multirow{2}{*}{$\mathrm{mFG}$ score } & $<8$ & $474(94.8 \%)$ & \multirow{2}{*}{$<0.005$} \\
\hline & & $>8$ & $26(5.2 \%)$ & \\
\hline
\end{tabular}

\section{Discussion}

The present study was conducted among women of reproductive age group (early) (15-30 years), to study clinical presentation of PCOS and associated clinical features. In the present study average age was $22.47+$ 3.44 years in range of 16 to 32 years. Majority $60.4 \%$ were in age group of 21 to 25 years, $26 \%$ were $<20$ years and only $13.6 \%$ were $>25$ years. In present study mean age at menarche was $13.52+1.28$ years in a range of 11 to 17 years. Majority $82.2 \%$ attained menarche at age $<15$ years and $17.8 \%>15$ years. Comparison of findings form other similar studies is given in table 6 . Majority $86.2 \%$ were unmarried and $13.8 \%$ were married. Swetha Balaji et $\mathrm{al}^{6}$ showed that all of the cases were unmarried $(100 \%)$. In the present study, all females had menstrual problems. Only 5.8\% complained of hirsutism rest $94.2 \%$ were normal. $13.4 \%$ had acne problems and $86.6 \%$ were normal. Only 69 females were married, out of them 5\% i.e 25 females had infertility. Study by Jayshree $\mathrm{J}_{\text {et }} \mathrm{al}^{7}$ in their study found that $2 \%$ had infertility. $13.2 \%$ complaint of excessive hair loss, while $21.2 \%$ of the females complaint of weight gain. Skin discoloration was seen among $32.6 \%$ females. Clinical features like menstrual abnormalities, hirsutism, infertility, and weight gain and skin discoloration were statistically significant. Mean $\mathrm{mFG}$ score was $6.32+3.33$ in a range of 2 to 30 . Majority 94.85 had score $<8$ and only $5.2 \%$ had $>8(\mathrm{p}=0.0001)$.

Diet was mixed type in $61 \%$ females and $39 \%$ were vegetarian. Only $4.6 \%$ females did regular exercise. Majority $75 \%$ had sedentary lifestyle, $25 \%$ did moderate work. Only $8.6 \%$ showed relevant family history Nitin Joseph et $\mathrm{al}^{8}$ in their study showed that $7.4 \%$ had positive family history. Study by Hussein B et $\mathrm{al}^{9}$ showed that $11.3 \%$ had relevant family history. Mean height was $152.2+4.51$ in a range of 142 to 161 $\mathrm{cm}$. majority $62.2 \%$ had height $>150 \mathrm{~cm}$. Majority $80.2 \%$ had weight $>50 \mathrm{kgs}$ and mean weight was $55.87+8.31$ and in a range of 32 to $72 \mathrm{~kg}$. $(\mathrm{p}=0.005)$. Mean BMI was $22.22+2.22$ in a range of 17.4 to 27.8 $\mathrm{kg} / \mathrm{m} 2$. Majority $89.6 \%$ had BMI $<25$ and only $10.4 \%$ had BMI > $25(\mathrm{p}=0.002)$. Mean WHR was $0.8+0.04$ in a range of 0.55 to 0.87 . Majority $59.2 \%$ had WHR $>0.8$ and $40.8 \%$ had WHR $<0.8$. Only $14.6 \%$ showed PCOS pattern on USG. $17 \%$ were diagnosed as PCOS and $83 \%$ were non PCOS. $21 \%$ had abnormal thyroid values. In present study majority $41.17 \%$ had phenotype 4 , followed by $36.47 \%$ had phenotype 1 , followed by $15.29 \%$ had type 2 and $7.05 \%$ had type 3 . Table number 6 shows comparison of findings from the present study with other similar studies.

Table 6: Comparison of findings from the present study and various similar studies

\begin{tabular}{|c|c|c|c|}
\hline S. No. & Variables & Present study & Other studies \\
\hline 1 & Mean age & $22.47+3.44$ years & $\begin{array}{c}\text { Joshi B et al }^{10}-18.15+2.4 \text { years } \\
\text { Rathod A et } \mathrm{al}^{11}-10-19 \text { years }\end{array}$ \\
\hline 2 & Age at menarche & $13.52+1.28$ years & $\begin{array}{c}\text { Joshi B et al }{ }^{10}-13.22+1.3 \\
\text { Rathod A et al }^{11}-16 \text { years }(65 \%)\end{array}$ \\
\hline 3 & Menstrual irregularities & $100 \%$ & $\begin{array}{l}\text { Rathod A et al }{ }^{11}-84.88 \% \\
\text { Nitin Joseph et } \text { al }^{8}-87.2 \%\end{array}$ \\
\hline 4 & Hirsuitism & $5.8 \%$ & $\begin{array}{l}\text { Joshi B et al }{ }^{10}-13.7 \% \\
\text { Jayshree J et al }{ }^{7}-5 \% \\
\text { Sanchez N et } \text { al }^{12}-7 \%\end{array}$ \\
\hline 5 & Acne & $13.4 \%$ & $\begin{array}{l}\text { Jayshree } \mathrm{J} \text { et } \mathrm{al}^{7}-33.5 \% \\
\text { Sanchez N et al }{ }^{12}-21 \%\end{array}$ \\
\hline 6 & Skin color changes & $32.6 \%$ & $\begin{array}{l}\text { Nitin Joseph et al } l^{8}-28.2 \% \\
\text { Swetha Balaji et } \mathrm{al}^{6}-23 \%\end{array}$ \\
\hline 7 & Weight gain & $21.2 \%$ & $\begin{array}{c}\text { Sanchez } \mathrm{N} \text { et al }{ }^{12-}-8732 \% \\
{\text { Radha P et al }{ }^{13}-12 \%}_{\text {(rural girls) \& } 52 \%}^{\text {(urban girls) }}\end{array}$ \\
\hline 8 & BMI & $22.22+2.22 \mathrm{~kg} / \mathrm{m} 2$ & $\begin{array}{c}\text { Joshi B et al }{ }^{10}-19.38+3.7 \mathrm{~kg} / \mathrm{m} 2 \\
\text { Lakshmi KS et } \mathrm{al}^{14}-28+7\end{array}$ \\
\hline 9 & History of thyroid disorder & $21 \%$ & Rathod A et al ${ }^{11}$ - only $1 \%$ \\
\hline
\end{tabular}




\begin{tabular}{|c|c|c|c|}
\hline & & & Swetha Balaji et al $^{6}-25$ cases \\
\hline 10 & Polycystic changes on USG & $14.6 \%$ & $\begin{array}{c}\text { Joshi B et al } 1^{10}-22.5 \% \\
\text { Swetha Balaji et } \text { al }^{6}-63 \%\end{array}$ \\
\hline 11 & Clinically diagnosed PCOD & $17 \%$ & $\begin{array}{c}\text { Jayshree J et al }{ }^{7}-856 \% \\
\text { Sanchez N et al }{ }^{12}-876.6 \%\end{array}$ \\
\hline
\end{tabular}

\section{Conclusion}

From the observations in the present study, it can be concluded that PCOS is a common disorder among young women. Menstrual problems are the commonest reason for gynecological OPD consultation among adolescent girls. Evaluation of bleeding problems in adolescents is justified, before considering them as normal physiological transition. Childhood obesity, sedentary lifestyle, lack of exercises, and popularity of junk food in adolescence are responsible for the increasing PCOS incidence in adolescent girls and is challenge for gynecologists treating them. Adolescent girls with menorrhagia need to be evaluated thoroughly earlier rather than later with the onset of symptoms, so that effective management can be started, and anemia with its consequences can be prevented. Health education classes to create awareness regarding adolescent gynecological problems with the help of menstrual calendar should be conducted regularly in school and colleges. Avoidance of junk food, healthy life style, yoga, etc. must be encouraged in adolescent girls. It must be a part of the school health program. Therefore, periodic screening is required particularly for those with positive family history of PCOS. This will enable early diagnosis of this condition so as to facilitate prompt referral and management to prevent long-term complications. Lifestyle modification for weight reduction and dietary modification along with counseling services for addressing emotional problems should support other management options. Hence, a multidisciplinary approach involving professionals is required to manage young women with this endocrine disorder. Early diagnosis of PCOS and its prompt treatment will help the girls to improve quality of life and prevent further health hazards.

\section{References}

1. Ehrmann DA. Polycystic Ovary Syndrome. N Engl J Med. 2005;352:1223-1236.

2. Jonard S, Dewailly D. Thefollicular excess in polycystic ovaries, due to intraovarian hyperandrogenism, may be the main culprit for the follicular arrest. Hum Reprod Update. 2004;10:107-117.

3. Teede H, Hutchison S, Zoungas S, Meyer C. Insulin resistance, the metabolic syndrome, diabetes, and cardiovascular disease risk in women with PCOS. Endocrine. 2006;30:45-53.

4. Rotterdam ESHRE/ASRM-Sponsored PCOS Consensus Workshop Group. Revised 2003 consensus on diagnostic criteria and long-term health risks related to polycystic ovary syndrome. Fertil Steril. 2004;81(1):19-25.
5. Chen Y, Yang D, Li L, Chen X. J Pediatr Adolesc Gynecol. 2008;21(6):347-50.

6. Balaji S, Amadi C, Prasad S, et al. Urban Rural Comparisons of Polycystic Ovary Syndrome Burden among Adolescent Girls in a Hospital Setting in India. Bio Med Research International. 2015;2015:158951. doi:10.1155/2015/158951.

7. Jayshree J. Upadhye, Chaitanya A. Shembekar. Awareness of PCOS (polycystic ovarian syndrome) in adolescent and young girls. Int J Reprod Contracept Obstet Gynecol. 2017;6(6):2297-2301.

8. Nitin Joseph, Aditya G. R. Reddy, Divya Joy, Vishakha Patel, Pooja Santhosh, Shatarupa Das, and Siddharth K. Reddy. Study on the proportion and determinants of polycystic ovarian syndrome among health sciences students in South India. J Nat Sci Biol Med. 2016;7(2):166-172.

9. Bayan Hussein, Shahla Alalaf. Prevalence and characteristics of polycystic ovarian syndrome in a sample of infertile Kurdish women attending IVF infertility. Open Journal of Obstetrics and Gynecology. 2013;3:577-585.

10. Beena Joshi, Srabani Mukherjee, Anushree Patil, Ameya Purandare, Sanjay Chauhan, and Rama Vaidya. A cross-sectional study of polycystic ovarian syndrome among adolescent and young girls in Mumbai, India. Indian J Endocrinol Metab. 2014;18(3):317-324.

11. Archana D. Rathod, Rohidas P. Chavan, Sandhya P. Pajai, Vijay Bhagat, Prachi Thool. Gynecological Problems of Adolescent Girls Attending Outpatient Department at Tertiary Care Center with Evaluation of Cases of Puberty Menorrhagia Requiring Hospitalization. The Journal of Obstetrics and Gynecology of India;66(S1):S400-S406.

12. Sanchez N. A life course perspective on polycystic ovary syndrome. Int J Womens Health. 2014;6:115- 22.

13. Radha P, Devi RS, Madhavi J. Comparative study of prevalence of polycystic ovarian syndrome in rural and urban population. $J$ Adv Med Dent Scie Res. 2016;4(2):90-5.

14. Lakshmi KS, Jayasutha J, Chandrasekar A. A study on prevalence of polycystic ovarian syndrome in a tertiary care hospital. Int J Pharmaceu Sci Res. 2015;6(1):383.

How to cite this article: Gaitonde V, Patil S, Patil S, Patil Y. Assessment of determinants of polycystic ovarian syndrome in women in reproductive age group attending tertiary healthcare facility in southern Maharashtra. Ind J Obstet Gynecol Res. 2018;5(3):372-376. 